\title{
An Observational Study on Correlation of Fasting and Postprandial Glycemic Status to various HbA1C Quintiles in Type II Diabetics.
}

\author{
SH Talib*, Bhattu SR**, Jayraj S. Korpe***. \\ *Professor \& Head, **Assistant Professor, ***Chief Resident \\ Department of Medicine, Mahatma Gandhi Missions Medical College \& Hospital, Aurangabad- 431003.
}

\begin{abstract}
Introduction: The exact contributions of postprandial and fasting glucose increments to overall hyperglycemia remain controversial. An observational prospective study is designed to know the relationship of the defined range of various values of glycosylated hemoglobin with fasting and postprandial glycemic status in pre-diabetics and diabetic subjects.
\end{abstract}

Methods \& Material: The 402 patients enrolled for this study are divided into 5 groups (Quintiles) depending upon their HbAlC levels.

Results: The mean value of Fasting Plasma Glucose (FPG) and Postprandial Plasma Glucose (PPG) increases with the increasing quintile of HbAlC. The Correlation Coefficient ( $r$-value) for the mean FPG increases with increasing HbAlC Quintiles while that of the mean PPG decreases with higher HbAlC Quintiles. Mean BMI is significantly and positively correlated with HbAlC Quintiles in Groups C, D and E. The occurrence of Diabetic Neuropathy is seen more with rising trends of HbAlC Quintiles.

Conclusion: With the severity of diabetes mellitus in relation to increased HbAIC values, attention should be paid more for better control of Fasting Plasma Glucose. When the values of HbAIC are near normal or in prediabetic range, glycemic control should be achieved by controlling postprandial plasma glucose since here fasting plasma glucose is negatively correlated. When the values of HbAlC remain at the moderate limit due attention is needed for controlling both the fasting and the postprandial plasma glucose, judiciously.

Key Words: Glyosylated Hemoglobin Quintiles, Fasting Plasma Glucose (FPG), Postprandial Plasma Glucose (PPG).

\section{Introduction:}

The exact contributions of postprandial and fasting glucose increments to overall hyperglycemia remain controversial. The glycosylated hemoglobin are minor components of adult hemoglobin which are obtained by cation exchange chromatography. In 1997 and 2003, the Expert Committee on Diagnosis and Classification of Diabetes Mellitus recognized an intermediate group of individuals whose glucose levels do not meet criteria for diabetes, yet are higher than those considered normal. These people were defined as having impaired fasting Glucose (IFG) fasting plasma glucose (FPG) levels $100 \mathrm{mg} / \mathrm{dl}$ to125 mg/dl, or impaired glucose tolerance (IGT) 2-h values in the oral glucose tolerance test (OGTT) of $140 \mathrm{mg} / \mathrm{dl}$ to $199 \mathrm{mg} / \mathrm{dl}$. Individuals with IFG and/or IGT have been referred to as having pre-diabetes, indicating the relatively high risk for the future development of diabetes. ${ }^{1}$ After an extensive review of both established and emerging epidemiological evidence, the International Expert Committee recommended the use of the HbA1C test to diagnose diabetes, with a threshold of $\geq 6.5 \%$. This decision has been affirmed by the ADA in 2010. The established glucose criteria for the diagnosis of diabetes also remain valid. These include the FPG $\geq 126 \mathrm{mg} / \mathrm{dl}$ wherein fasting is defined as no caloric intake for at least $8 \mathrm{~h}$ OR 2-h PG $\geq 200 \mathrm{mg} / \mathrm{dl}$. Additionally, patients with severe hyperglycemia such as those who present with severe classic hyperglycemic symptoms or hyperglycemic crisis can continue to be diagnosed when random (or casual) plasma glucose is $\geq 200 \mathrm{mg} / \mathrm{dl}$.

The present study is designed to know the relationship of the defined range of various values of glycosylated hemoglobin with fasting and postprandial glycemic status in pre-diabetics and diabetic patient with / without oral hypoglycemic agents.

\section{Methods \& Material:}

402 patients of Diabetes Mellitus were enrolled for this prospective observational study.

\section{Inclusion Criteria:}

1. The Patients of type II diabetes mellitus who were receiving oral hypoglycemic agents for more than 3 months. 
2. The Patients of type II diabetes mellitus without any medications (New Cases).

3. The cases diagnosed as pre-diabetics.

\section{Exclusion criteria:}

1. All the cases of Type I Diabetes Mellitus.

2. Patients of type II Diabetes Mellitus who were on oral hypoglycemic agents for less than three months period.

3. All cases of type II Diabetes Mellitus who received insulin in the past 3 months.

4. Anemic patients with Hemoglobin level less than $9.0 \mathrm{gm} \%$.

5. Patients of Type II Diabetes Mellitus with known abnormal hemoglobinopathies.

6. Patients of Type II Diabetes Mellitus with changes in diet or lifestyle within the previous 3 months.

The study population was divided into 5 groups (Quintiles) depending upon their $\mathrm{HbA} 1 \mathrm{C}$ levels:

Group A- having HbA1C levels less than 5.6

Group B- HbA1C levels between 5.7 to 6.4

Group C- HbA1C levels between 6.5 to 8.2

Group D- HbA1C levels between 8.3 to 10.2

Group E- HbA1C levels more than 10.3

The groups formed as above include persons with Impaired Fasting Glucose (IFG) or Impaired Glucose Tolerance (IGT) or Pre-diabetics, who have a high risk of developing Diabetes Mellitus in future. The history and life style details were recorded. The cases were analyzed for Glycosylated Hemoglobin, Fasting Plasma Glucose \& 2 Hours Plasma Glucose. The patients were screened for Hemoglobin \%, Body Mass Index, evidence for Diabetic Retinopathy on Fundoscopy and Neuropathy, clinically.

Fasting and postprandial plasma glucose levels are done on a photometric instrument called as "Dimension". The estimation of Glycosylated Hemoglobin levels has been conducted by the NycoCard Kit.

\section{Observations And Results:}

A total of 402 patients were included in this study. Out of the 402 patients, $205(51 \%)$ are males and $197(49 \%)$ are females. The Mean age for male population is $55.04 \pm 13.22$ years while that of the female population is $50.50 \pm 10.97$ years. The Male to female ratio is $1.04: 1$. There is no significant gender variation noted in the overall population. Out of 402 cases studied the maximum incidence of patients occurred in the age group of 41-50 years and the minimum occurred in the age group of $81-90$ years. No Female patient is seen in age group of 81-90 years and there is significant difference of gender noted in the age groups of 70 years and above.

The total number of study population is distributed into 5 groups (Quintiles) depending upon their $\mathrm{HbA1C}$ levels. There is no significant percentile co-relationship of Gender with HbA1C Quintiles.

Table I \& Fig. I describes the number of patients in each Quintile of HbA1C. Maximum Number of patients found in Group C (6.5\%-8.2 \%), whereas the minimum in Group A $(\leq 5.6 \%)$. The mean value of Fasting Plasma Glucose (FPG) and Postprandial Plasma Glucose (PPG) increases with the increasing quintile of HbA1C.

Table II and Fig. II describes the mean values of FPG \& PPG is positively correlated with Group C, Group D and Group E. The r- value for Mean FPG increases with increasing HbA1C Quintiles whereas that of Mean PPG Decreases with increasing HbA1C Quintile. Mean FPG \& Mean PPG is negatively correlated with Group B more so with Mean PPG. Mean PPG is significant in Group-A ( $\mathrm{p}=0.024)$, whereas mean FPG is not significant in Group-A ( $\mathrm{p}=0.419)$.

Table III and Fig.III shows that both mean FPG \& PPG show deviation with rising HbA1C Quintiles. Mean FPG is more significantly deviated than Mean PPG in Group E. The Percentage Deviation seen in group D for mean FPG \& PPG is almost equal, suggesting that controlling both FPG and PPG is needed in moderate range of HbA1C. Mean PPG is most significantly deviated in Group A when comparing with Mean FPG, suggesting that controlling PPG is more needed than FPG in diabetics with near normal HbA1C.The findings of Percentage Deviation are similar to those with correlation coefficient ( $r$ - value).

Table IV describes the Obesity Class tends to rise significantly from Healthy to Obese with rising trends of $\mathrm{HbA} 1 \mathrm{C}$ Quintiles.

Table V shows the occurrence of DR is more with rising trend of HbA1C. The Clinical Grades of Diabetic Retinopathy tends to rise from mild to severe with rising trends of $\mathrm{HbA1C}$ quintiles.

Table VI describes The occurrence of Diabetic Neuropathy in Diabetics. It is observed that the occurrence of Diabetic Neuropathy increases with rising trends of $\mathrm{HbA1C}$ Quintiles. Even in the pre diabetic range out of 51 cases, 37 had no neuropathy while 14 (27.45\%) had clinical evidence of neuropathy. The 
evidence of neuropathy is noted in the Pre-diabetic as well as the diabetic range, hence neurological examination in cases of pre-diabetics is mandatory even when the individual is asymptomatic.

\section{Discussion:}

The present study with 402 cases is designed to know the relationship of the defined range of various values of glycosylated hemoglobin with fasting and postprandial glycemic status in pre-diabetics and diabetic patient with or without oral hypoglycemic agents. The groups (quintiles) of HbA1C are formed in accordance with the ADA Criteria (2010) $)^{2}$.

A study, conducted by Avignon et al (1997) ${ }^{7}$ found that post lunch plasma glucose and extended post lunch plasma glucose was more reliable in predicting poor glycemic control than pre-breakfast or pre-lunch plasma glucose. Similarly, improvements in HbA1C levels were noted in a study by Bastyr et al (2000) ${ }^{\mathbf{8}}$, which showed that therapy focused on lowering postprandial glucose found better in lowering glycated hemoglobin levels.

To test the effect of overall glycemic control, Monnier et al $(2003)^{9}$ analyzed the diurnal glycemic profiles of type 2 diabetic patients investigated with various quintiles of HbA1C. This study was based on 290 non-insulin- and non-acarbose using patients with type 2 diabetes. Plasma Glucose (PG) concentrations were determined as fasting, postprandial and post-absorptive periods. The authors observed that the relative contribution of postprandial glucose decreased progressively from the lowest $69.7 \%$ to the highest quintile of HbA1C $30.5 \%(P<0.001)$, whereas the relative contribution of fasting glucose increased gradually with increasing levels of HbA1C: $30.3 \%$ in the lowest vs. $69.5 \%$ in the highest quintile $(P<0.001)$. The authors concluded that the relative contribution of postprandial glucose excursions is predominant in fairly controlled patients, whereas the contribution of fasting hyperglycemia increases gradually with diabetes worsening.

In the present study, the total number of study population is distributed into 5 groups (Quintiles) depending upon their HbA1C levels. There is no significant percentile co-relationship of gender with HbA1C quintiles. The mean values of both the Fasting Plasma Glucose (FPG) and the Postprandial Plasma Glucose (PPG) increases with the rising trend of HbA1C quintile (Table I \& Fig.I). Fasting Plasma Glucose is more significantly correlated with the HbA1C levels than the postprandial plasma glucose in the uncontrolled diabetics (Group-E), whereas the postprandial plasma glucose is more significantly correlated in the lower ranges of HbA1C (Group-A \& Group-B). In cases of diabetes mellitus in Group-C \& Group-D, the r-values for both the FPG and the PPG found equal and significant (Table II and fig. II).

We conclude that, with the severity of diabetes mellitus in relation to increased $\mathrm{HbA1C}$ values, attention should be paid more for better control of Fasting Plasma Glucose. When the values of HbA1C are near normal or in pre-diabetic range, glycemic control should be achieved by controlling postprandial plasma glucose since here fasting plasma glucose is negatively correlated. When the values of HbA1C remain at the moderate limit due attention is needed for controlling both the fasting and the postprandial plasma glucose, judiciously.

Further, significant correlations are noted between the body mass index and the HbA1C level in the patients with diabetes mellitus in Group- $\mathrm{C}(\mathrm{p}=0.007)$, Group-D $(\mathrm{p}=0.023)$ and in Group-E $(\mathrm{p}=0.004)$. The obesity class tends to rise significantly from healthy to obese with the rising trends of HbA1C quintiles (Table IV). The presence of diabetic retinopathy is significantly noted in $300(74.62 \%)$ cases of the total study population. The clinical grades of diabetic retinopathy tends to rise from mild to severe with rising trends of HbA1C quintiles (Table V). The presence of diabetic neuropathy is noted in $187(46.51 \%)$ cases of the total study population. Diabetic neuropathy is seen more with rising trends of HbA1C quintiles, (Group-D \& E) (Table VI). In the pre-diabetic range (Group-B) out of 51 patients 14 (27.45\%) patients had clinical evidence of diabetic neuropathy. Hence, the neurologic examination in pre-diabetics is mandatory even when the individual is asymptomatic.

\section{Conclusion:}

With the severity of diabetes mellitus in relation to increased $\mathrm{HbA1C}$ values, attention should be paid more for better control of Fasting Plasma Glucose. When the values of HbA1C are near normal or in prediabetic range, glycemic control should be achieved by controlling postprandial plasma glucose since here fasting plasma glucose is negatively correlated. When the values of $\mathrm{HbA1C}$ remain at the moderate limit due attention is needed for controlling both the fasting and the postprandial plasma glucose, judiciously. Diabetic neuropathy is seen more with rising trends of $\mathrm{HbA1C}$ quintiles. The obesity class tends to rise significantly from healthy to obese with the rising trends of $\mathrm{HbA} 1 \mathrm{C}$ quintiles. The clinical grades of diabetic retinopathy tends to rise from mild to severe with rising trends of HbA1C quintiles. Diabetic neuropathy is observed in pre-diabetics and diabetics. Hence, the neurologic examination in pre-diabetics is mandatory even when the individual is asymptomatic. 
Table I: Comparison of various HbA1C Quintiles with number of patients and Mean Fasting Plasma Glucose and Mean Postprandial Plasma Glucose levels:

\begin{tabular}{|c|c|c|c|}
\hline $\begin{array}{c}\text { Groups } \\
\text { Quintile) }\end{array}$ & $\begin{array}{c}\text { Number of patients } \\
\text { (Percent of Total Study } \\
\text { Population) }\end{array}$ & $\begin{array}{c}\text { Mean FPG (SD) } \\
\mathrm{mg} / \mathrm{dl}\end{array}$ & $\begin{array}{c}\text { Mean PPG (SD) } \\
\mathrm{mg} / \mathrm{dl}\end{array}$ \\
\hline Group A & $29(7.2 \%)$ & $101.35(12.16)$ & $139.76(24.54)$ \\
\hline Group B & $51(12.68 \%)$ & $103.31(18.40)$ & $180.49(40.73)$ \\
\hline Group C & $131(32.5 \%)$ & $119.07(29.67)$ & $199.23(47.06)$ \\
\hline Group D & $80(20 \%)$ & $171.55(60.76)$ & $275.81(75.50)$ \\
\hline Group E & $111(27.61 \%)$ & $244.52(78.48)$ & $366.32(108.92)$ \\
\hline TOTAL & $402(100 \%)$ & - & - \\
\hline
\end{tabular}

Table II: Correlation between HbA1C groups with FPG and PPG levels:

\begin{tabular}{|c|c|c|c|c|c|c|c|}
\hline \multirow{2}{*}{ Group } & \multirow{2}{*}{$\begin{array}{c}\text { No. of } \\
\text { patients }\end{array}$} & \multicolumn{2}{|c|}{ Fasting Plasma Glucose (FPG) } & \multicolumn{3}{c|}{ Postprandial Plasma Glucose (PPG) } \\
\cline { 3 - 8 } & 29 & 101.35 & -0.283 & $\mathrm{P}=0.419 \mathrm{NS}$ & 139.76 & 0.419 & $\mathrm{P}=0.024 \mathrm{~S}$ \\
\hline Group A & 29 & r-value & p-value & Mean & r-value & $\mathrm{p}$-value \\
\hline Group B & 51 & 103.31 & -0.316 & $\mathrm{P}=0.024 \mathrm{~S}$ & 180.49 & -0.360 & $\mathrm{P}=0.009 \mathrm{~S}$ \\
\hline Group C & 131 & 119.07 & 0.317 & $\mathrm{P}=0.000 \mathrm{~S}$ & 199.23 & 0.472 & $\mathrm{P}=0.000 \mathrm{~S}$ \\
\hline Group D & 80 & 171.55 & 0.211 & $\mathrm{P}=0.040 \mathrm{~S}$ & 275.81 & 0.273 & $\mathrm{P}=0.013 \mathrm{~S}$ \\
\hline Group E & 111 & 244.52 & 0.528 & $\mathrm{P}=0.000 \mathrm{~S}$ & 366.32 & 0.214 & $\mathrm{P}=0.021 \mathrm{~S}$ \\
\hline
\end{tabular}

(If $P \geq 0.05$ Not Significant, $P<0.05$ Significant)

Table III: Group wise Percentage Deviation of FPG, PPG \& HbA1C from the Cut off points of diabetes Mellitus:

\begin{tabular}{|c|c|c|c|}
\hline GROUPS & FPG mg/dl & PPG mg/ dl & HbA1C \% \\
\hline Pre-diabetic Range & 101 to 125 & 140 to 199 & $5.7-6.4$ \\
\hline Diabetic Range & $\geq 126$ & $\geq 200$ & $\geq 6.5$ \\
\hline Cut off values & $125 \mathrm{mg} / \mathrm{dl}$ & $199 \mathrm{mg} / \mathrm{dl}$ & $6.5 \%$ \\
\hline Group A & $-19.2 \%$ & $-24.63 \%$ & $-19.23 \%$ \\
\hline Group B & $-17.6 \%$ & $-9.55 \%$ & $-5.85 \%$ \\
\hline Group C & $-4.8 \%$ & $1.84 \%$ & $13.85 \%$ \\
\hline Group D & $37.6 \%$ & $38.19 \%$ & $43.85 \%$ \\
\hline Group E & $95.2 \%$ & $83.42 \%$ & $81.85 \%$ \\
\hline
\end{tabular}

The Percentage deviation is recorded from defined cut off values for pre-diabetic and diabetic ranges as per ADA Criteria (2010) ${ }^{2}$.

Table IV: Classification of Overweight \& Obesity by Body Mass Index (BMI): (NIH Classification 1998) ${ }^{3}$

\begin{tabular}{|c|c|c|c|c|c|c|c|c|}
\hline $\begin{array}{l}\text { CLASS } \\
\left(\mathrm{kg} / \mathrm{m}^{2}\right)\end{array}$ & Group & $\begin{array}{l}\text { Group } \\
\text { B }\end{array}$ & $\begin{array}{l}\text { Group } \\
\text { C }\end{array}$ & $\begin{array}{l}\text { Group } \\
\text { D }\end{array}$ & Group E & Total & $\begin{array}{l}\text { Chi- } \\
\text { square } \\
\text { Value } \\
\end{array}$ & $\mathrm{P}$ value \\
\hline $\begin{array}{l}\text { Underweight } \\
(<18.5)\end{array}$ & 00 & 00 & 00 & 00 & 00 & 00 & \multirow{7}{*}{194} & \multirow{7}{*}{$\begin{array}{c}\mathrm{P}=0.000 \\
\mathrm{~S}\end{array}$} \\
\hline $\begin{array}{l}\text { Healthy weight / Normal } \\
(18.5-24.9)\end{array}$ & 18 & 31 & 28 & 05 & 01 & 83 & & \\
\hline $\begin{array}{l}\text { Overweight } \\
(25.0-29.9)\end{array}$ & 10 & 20 & 87 & 45 & 39 & 201 & & \\
\hline $\begin{array}{c}\text { Obesity I } \\
(30.0-34.9)\end{array}$ & 01 & 00 & 14 & 30 & 64 & 109 & & \\
\hline $\begin{array}{c}\text { Obesity II } \\
(35.0-39.9)\end{array}$ & 00 & 00 & 02 & 00 & 07 & 09 & & \\
\hline $\begin{array}{l}\text { Obesity III / Extreme } \\
\text { Obesity }(\geq 40)\end{array}$ & 00 & 00 & 00 & 00 & 00 & 00 & & \\
\hline Total & 29 & 51 & 131 & 80 & 111 & 402 & & \\
\hline
\end{tabular}

(If $P \geq 0.05$ Not Significant, $P<0.05$ Significant) 
Table V: Grading of Diabetic Retinopathy with various groups of HbA1C:

[The Diabetic Retinopathy Study Research Group- DRS Classification $(1981)^{4,5,6}$ ]

\begin{tabular}{|c|c|c|c|c|c|c|c|c|}
\hline $\begin{array}{c}\text { Grades of Diabetic } \\
\text { Retinopathy }\end{array}$ & $\begin{array}{c}\text { Group } \\
\text { A }\end{array}$ & $\begin{array}{c}\text { Group } \\
\text { B }\end{array}$ & $\begin{array}{c}\text { Group } \\
\text { C }\end{array}$ & $\begin{array}{c}\text { Group } \\
\text { D }\end{array}$ & Group E & Total & $\begin{array}{c}\text { Chi- } \\
\text { square } \\
\text { Value }\end{array}$ & p-value \\
\hline $\begin{array}{c}\text { No Diabetic } \\
\text { Retinopathy }\end{array}$ & 21 & 32 & 46 & 01 & 02 & 102 & & \\
\hline $\begin{array}{c}\text { Mild Non- } \\
\text { Proliferative Diabetic } \\
\text { Retinopathy }\end{array}$ & 06 & 17 & 71 & 41 & 26 & 161 & \multirow{2}{*}{ P=0.000 } \\
\hline $\begin{array}{c}\text { Moderate Non- } \\
\text { Proliferative Diabetic } \\
\text { Retinopathy }\end{array}$ & 02 & 02 & 13 & 34 & 67 & 118 & S \\
\hline $\begin{array}{c}\text { Severe Non- } \\
\text { Proliferative Diabetic } \\
\text { Retinopathy }\end{array}$ & 00 & 00 & 01 & 04 & 14 & 19 & 02 & \\
\hline $\begin{array}{c}\text { Proliferative Diabetic } \\
\text { Retinopathy }\end{array}$ & 00 & 00 & 00 & 00 & 02 & 00 & & \\
\hline $\begin{array}{c}\text { Clinically Significant } \\
\text { Macular Edema }\end{array}$ & 00 & 00 & 00 & 00 & 00 & 00 & \\
\hline Total & 29 & 51 & 131 & 80 & 111 & 402 & \\
\hline
\end{tabular}

(If $P \geq 0.05$ Not Significant, $P<0.05$ Significant)

Table VI: Occurrence of Diabetic Neuropathy:

\begin{tabular}{|c|c|c|c|c|c|c|c|c|}
\hline $\begin{array}{l}\text { Diabetic } \\
\text { Neuropathy }\end{array}$ & Group A & Group B & Group C & $\begin{array}{l}\text { Group } \\
\text { D }\end{array}$ & $\begin{array}{l}\text { Group } \\
\text { E }\end{array}$ & Total & $\begin{array}{l}\text { Chi- } \\
\text { square } \\
\text { test }\end{array}$ & p-value \\
\hline Present & 06 & 14 & 48 & 43 & 76 & 187 & \multirow{3}{*}{43.5} & \multirow{3}{*}{$P=0.000 S$} \\
\hline Absent & 23 & 37 & 83 & 37 & 35 & 215 & & \\
\hline Total & 29 & 51 & 131 & 80 & 111 & 402 & & \\
\hline
\end{tabular}

(If $P \geq 0.05$ Not Significant, $P<0.05$ Significant)

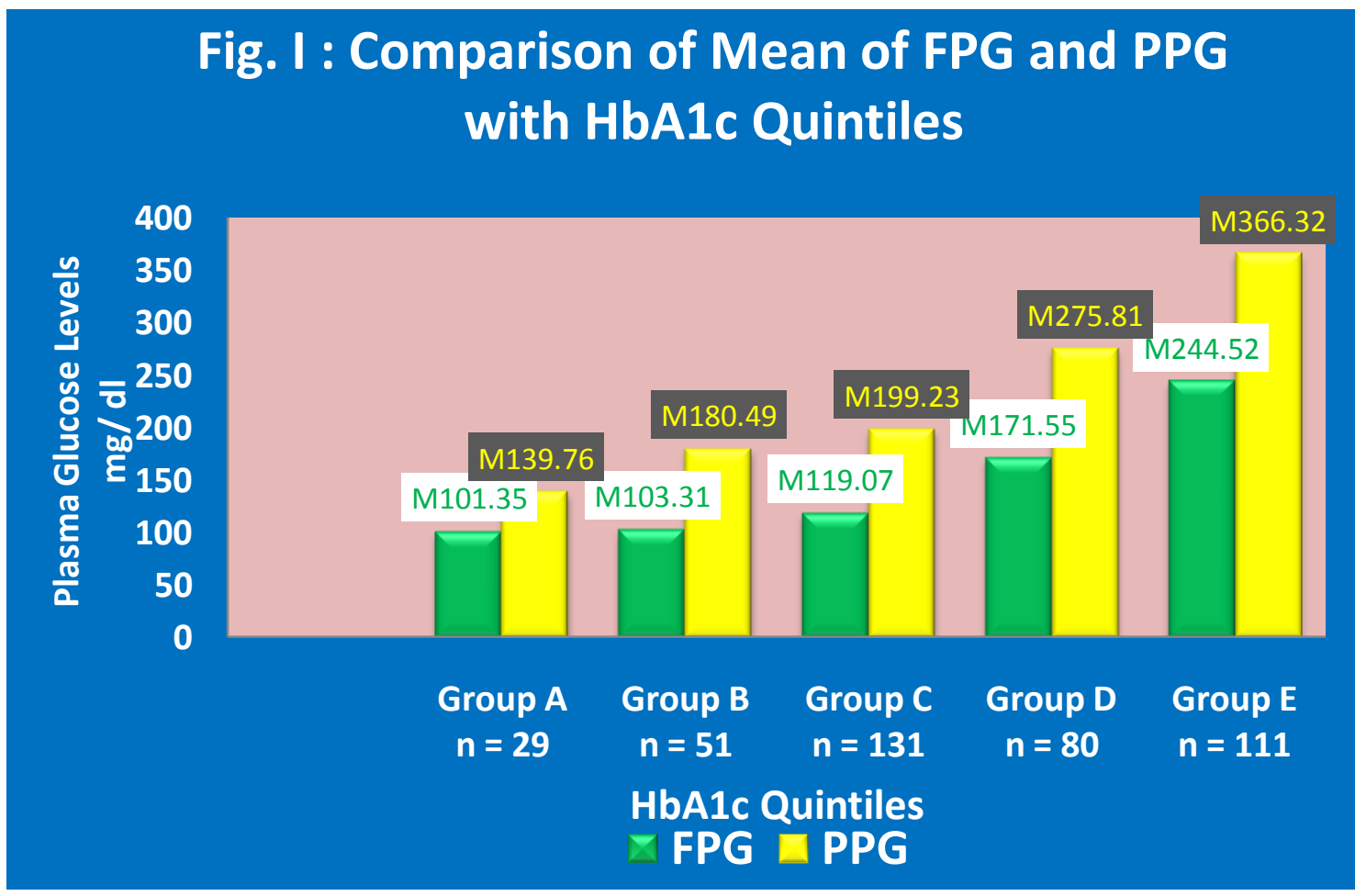




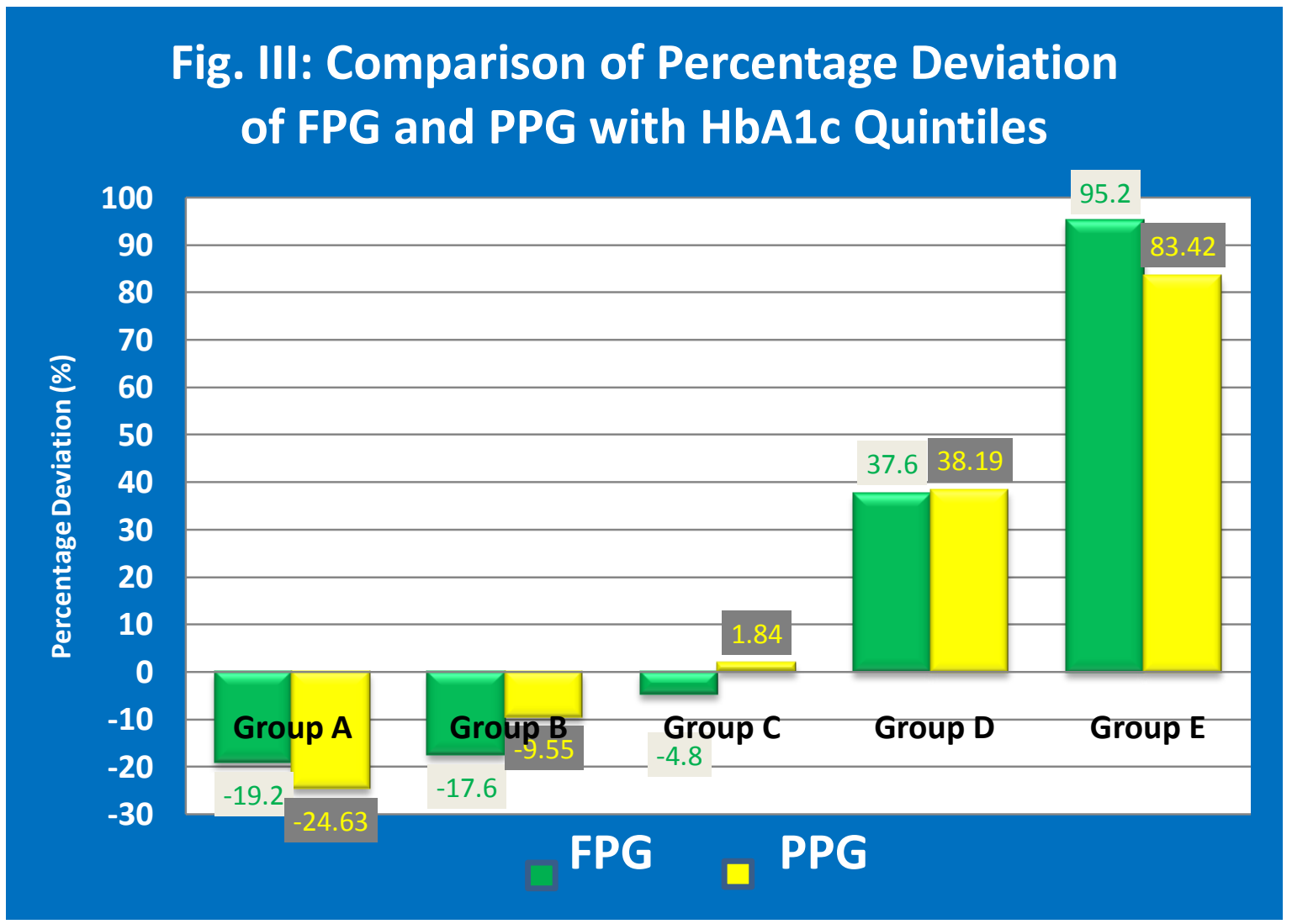

\section{Legends to figures:}

Fig. I: Bar Diagram showing comparison between the Mean of Fasting Plasma Glucose (FPG) and Postprandial Plasma Glucose (PPG) in various HbA1C Quintiles

Key: $\mathbf{x}$ axis $=$ Plasma Glucose Level, $\mathbf{y}$ axis $=$ HbA1C Quintiles, $n=$ number of cases $M=$ Mean Value, $\mathbf{F P G}=$ Fasting Plasma Glucose, PPG = Postprandial Plasma Glucose

Fig. II: Bar Diagram showing Comparison of Correlation Coefficient (r-value) of Mean Fasting Plasma Glucose (FPG) and Mean Postprandial Plasma Glucose (PPG) with various HbA1C Quintiles

Key: $\quad$ FPG - Fasting Plasma Glucose, PPG - Postprandial Plasma Glucose, r-value - Correlation Coefficient

Fig. III: Bar Diagram showing comparison between Percentage Deviation of Mean Fasting Plasma Glucose (FPG) and Mean Postprandial Plasma Glucose (PPG) with HbA1C Quintiles.

Key: $\quad$ FPG - Fasting Plasma Glucose, $\quad$ PPG - Postprandial Plasma Glucose

\section{References:}

[1]. International Expert Committee report on the role of the A1C assay in the diagnosis of diabetes. Diabetes Care 2009; 32:1327-34

[2]. Diagnosis and Classification of Diabetes Mellitus. Diabetes Care 2010; 33(1): S62-9.

[3]. Clinical Guidelines on the Identification, Evaluation and Treatment of Overweight and Obesity in Adults. The Evidence Report 1998. NIH Publication No. 98-4083.

[4]. Fong DS, Aiello LP, Ferris FL, Klein R. Diabetic Retinopathy. Diabetes Care 2004; 27(10): 2540-53.

[5]. Early Treatment Diabetic Retinopathy Study Research Group. Early Treatment Diabetic etinopathy Study design and baseline patient characteristics. ETDRS report number 7. Ophthalmology 1991; 98:742.

[6]. The Diabetic Retinopathy Study Research Group: A modification of the Airlie House classification of diabetic retinopathy. Invest Ophthalmol Vis Sci.1981; 21:210-26.

[7]. Avignon A, Radauceanu A, Monnier L. Non-fasting plasma glucose is a better marker of diabetic control than fasting plasma glucose in type two diabetes. Diabetes Care 1997; 20: 1822-26.

[8]. Bastyr EJ, Stuart CA, Brodows RG, Schwartz S, Graf CJ, Zagar A et al. Therapy focused on lowering postprandial glucose, not fasting glucose, may be superior for lowering HbA1c. Diabetes Care 2000; 23:1236-41.

[9]. Monnier L, Lapinski H, Colette C. Contributions of fasting and postprandial plasma glucose increments to the overall diurnal hyperglycemia of type 2 diabetic patients. Diabetes Care 2003; 26:881-85. 